\title{
SISTEM PENDUKUNG KEPUTUSAN PEMILIHAN ALAT KONTRASEPSI TERBAIK MENGGUNAKAN METODE SMART (SIMPLE MULTI ATTRIBUTE RATING TECHNIQUE ) BAGI KELUARAGA BERENCANA
}

\author{
Rizky Maulana ${ }^{1}$, Nining Suryani ${ }^{2}$, Duwi Cahya Putri Buani ${ }^{3}$ \\ ${ }^{1}$ Sistem Informasi, STMIK Nusa Mandiri \\ ${ }^{2}$ Sistem Informasi, Universitas Bina Sarana Informatika \\ ${ }^{3}$ Teknik Informasi, STMIK Nusa Mandiri \\ 1rizkymaulana9707@gmail.com,nining.nns@bsi.ac.id, 3duwi.dcp@nusamandiri.ac.id
}

\section{Abstract}

The growth rate in Indonesia continues to increase and is still relatively high. With the improvement in health services, the morality rate is low, while the birth rate remains high. Coupled with many types of contraceptives, it makes couple of childbearing age confused about which one to use. This is what causes the growth rate to be high. Therefore, efforts to determine population size are by determining the best contraceptive use for couples of childbearing age. This method uses a decision support system using the SMART method (Simple Multi-Attribute Rating Technique) with 40 respondents and uses a sampling technique using a simple random sampling method with the formula 40/3 =13,333 rounded up to 14 respondents. And for the types of contraceptives used in this study, namely the Pill, Injection, Implant, Intra-Uterine Device, Vasectomy, Tubectomy. From the research results, it was found that of the six types of contraceptives, the final value was obtained (birth control pills $=3.7$ ), (injection $=36.4$ ), $($ implant $=28.9),(I U D=55.0),($ vasectomy $=48.3),($ Tubectomy $=51.2)$. This study resulted in a decision using the SMART method for selecting the best contraceptive method, namely the type of birth control pill with a final value of 3.7. This lowest value determines the results of the respondent's questionnaire which means that there are not many obstacles in the use of this contraceptive.

Keywords: contraception, decision support system, SMART method (Simple Multi-Attribute Rating Technique).

\begin{abstract}
Abstraksi
Laju pertumbuhan di Indonesia terus bertambah dan relatif masih tinggi. Dengan adanya perbaikan pelayanan kesehatan dapat menyebabkan tingkat kelahiran tinggi sedangkan. tingkat kematian rendah. Ditambah dengan banyak jenis alat kontrasepsi membuat pasangan usia subur bingung menggunakan alat kontrasepsi yang mana. Hal ini yang menyebabkan laju pertumbuhan jadi tinggi. Oleh karenanya menetukan penggunaan alat kontrasepsi yang terbaik untuk pasangan usia subur merupakan upaya untuk menekan jumlah penduduk. Metode ini menggunakan sistem pendukung keputusan metode SMART ( Simple Multi Attribute Rating Technique ) dengan 40 responden dan menggunakan teknik pengambilan sampel menggunakan metode simple random sampling dengan rumus $40 / 3=13,333$ dibulatkan menjadi 14 responden. Dalam penelitian ini menggunakan jenis alat kontrasepsi yaitu pil KB, Suntik, Implant, Intra Uterine Device, Vasektomi, Tubektomi. Dari hasil penelitian didapatkan bahwa dari enam jenis alat kontrasepsi tersebut di dapat nilai akhir $($ Pil KB $=3,7),($ Suntik $=36,4),($ Implant $=28,9)$, (IUD $=55,0)$,
\end{abstract}


$($ Vasektomi $=48,3),($ Tubektomi $=51,2)$. Penelitian ini menghasilkan sebuah keputusan dengan metode SMART untuk pemilihan alat kontrasepsi terbaik yaitu jenis Pil KB dengan nilai akhir 3,7. Nilai terendah ini menentukan hasil dari kuisoner responden yang berarti tidak banyak kendala dalam penggunaan alat kontrasepsi ini.

Kata kunci: Alat Kontrasepsi, sistem pendukung keputusan. Metode SMART (Simple Multi Attribute Rating Techinuque).

\section{Introduction}

Dengan terus bertambahnya penduduk Indonesia, BKKBN (Badan Kependudukan Keluarga Berencana Nasional) sangat aktif dalam mempromosikan penggunaan alat kontrasepsi untuk menciptakan kesadaran bahwa keluarga besar tidaklah sesuai. Dikarenakan banyaknya jenis alat kontrasepsi membuat pasangan usia subur bingung untuk menggunakan yang mana, karena dibutuhkan pengetahuan yang luas untuk mendapatkan alat kontrasepsi yang sesuai. Bahkan banyak keluarga yang memakai alat kontrasepsi berdasarkan saran dari keluarga atau hanya sekedar ikut-ikut teman kerabatnya. Selain pasangan usia subur, ada pula yang sudah pernah melakukan $\mathrm{KB}$ namun mengalami kegagalan dan memilih ganti cara karena mengalami kehamilan ketika masih menggunakan kontrasepsi. Kelahiran dan kematian menentukan laju pertumbuhan penduduk. Laju pertumbuhan penduduk masih relatif tinggi merupakan masalah yang terdapat di Indonesia. Tingkat kelahiran tetap tinggi sedangkan tingkat kematian rendah maka perlu adanya penekanan tingkat kelahiran. Hal ini menjadi penyebab utama ledakan jumlah penduduk. Oleh karena itu upaya menekan jumlah penduduk dengan cara menggalangkan program keluarga berencana salah satunya dengan metode kontrasepsi jangka panjang yaitu Intrauterine Device (IUD) disebut juga spiral atau coil (Studi et al., 2018).

Pemilihan alat kontrasepsi secara efektif harus didasari dengan konseling yang dilakukan yaitu dengan proses pemberian informasi secara obyektif dan rinci atau detail, yang bertujuan untuk meningkatkan keberhasilan lebih lama serta mencerminkan baiknya kualitas pelayanan yang diberikan. Karena setiap metode memiliki kekurangan dan kelebihan masing-masing meskipun sudah di pertimbangkan untung dan ruginya kontrasepsi (Lontaan \& Dompas, 2014). Pertambahan penduduk merupakan salah satu masalah yang terjadi pada negara berkembang, hal ini mengakibatkan terjadinya permasalahan seperti ketersediaan lahan, kerusakan lingkungan, kebutuhan air dan udara bersih, kekurangan makanan dan beberapa masalah lainnya. Salah satu pencegahan dari pertambahan penduduk yang begitu pesat adalah dengan menekan pertumbuhan jumlah penduduk, dengan cara program Keluarga Berencana (KB) (Naafian et al., 2016). Penelitian sebelumnya dengan judul Sistem Pendukung Keputusan Pemilihan Metode Kontrasepsi di Puskesmas II Colomadu Dengan Algoritma Naïve Bayes berfokus pada prediksi pemilihan Metode Kontrasepsi yang hasil prediksinya adalah $82,2 \%$ (Naafian et al., 2016). Penelitian berikutnya dengan judul Pemilihan Alat Kontrasepsi dalam Rahim (AKDR) pada akseptor Keluarga Berencana yang berfokus pada Hubungan karakteristik ibu dengan pemilihan alat kontrasepsi dalam rahim (AKDR) pada akseptor KB di Puskesmas Kramatwatu Serang Banten menggunakan metode cross sectional dengan 82 responden akseptor $\mathrm{KB}$ dan menggunakan instrumen check list (Meilani \& Tunggali, 2020).

Dalam proses pengambilan keputusan banyak metode yang dapat digunakan. Salah satunya adalah metode Simple Multi Attribute Rating Technique atau yang disebut SMART. Pada tahun 1997 metode 
pengambilan keputusan multi kriteria dikembangkan oleh Edward. Setiap alternatif mencakup sejumlah kriteria yang mempunyai nilai-nilai dan setiap kriteria mempunyai bobot yang mendeskripsikan seberapa penting dibandingkan dengan kriteria lain, teori inilah yang mendasari teknik pengambilan keputusan multi kriteria. Untuk menilai setiap alternatif agar diperoleh alternatif paling baik menggunakan pembobotan (Novianti et al., 2016). Sedangkan dalam penelitian ini menunjukan alat kontrasepsi mana yang terbaik yang dapat digunakan oleh masyarakat serta penggunaan Metode Simple Attribute Rating Technique (SMART).

Metode Simple Attribute Rating Technique atau yang biasa disingkat SMART merupakan metode pengambilan keputusan multi attribute. Teknik pengambilan keputusan multi attribute ini digunakan untuk mendukung pembuat keputusan dalam memilih beberapa alternatife. Setiap pembuat keputusan harus memiliki sebuah alternatif yang sesuai dengan tujuan yang dirumuskan (Irawan et al., 2019).

Metode SMART dapat melakukan pengambilan keputusan yang multiatribut (Andani, 2019) dan juga mampu menyelesaikan masalah dengan multi kriteria (Suryanto \& Safrizal, 2015) (Saleh, 2018) (Novianti et al., 2016). Merode SMART dapat dijadikan alat untuk membantu mengambil keputusan yang akurat karena dengan adanya multikriteria dalam tahapannya (Safii \& Anggi Saputri, 2018)(Herlinda \& Husain, 2019).

\section{Materials and Methods}

SMART adalah metode yang digunakan pengambilan keputusan yang secara keseluruhan dapat menghitung beberapa hal yang memiliki sifat kualitatif \& kuantitatif. Pembobotan merupakan cara yang dipakai dalam metode ini. Pada metode ini, penentuan keputusan menggunakan beberapa parameter. Pemberian range nilai dan bobot berbeda-beda sesuai dengan seberapa penting dari parameternya. Pengambilan keputusan yang fleksibel salah satunya adalah SMART. Karena kesederhanaannya dalam menanggapi kebutuhan pembuat keputusan dan caranya menganalisa respon, hal inilah membuat banyak yang menggunakan metode SMART. Analisa yang terlibat adalah transparan sehingga metode ini memberikan pemahaman masalah yang tinggi dan dapat diterima oleh pembuat keputusan.

\subsection{Proses pemodelan metode SMART.}

Dalam penggunaan metode SMART adalah Menentukan persentase bobot kriteria. Penentuan bobot kriteria menggunakan rumus dari pembobotan ROC (Rank Order Centroid), pemberian bobot pada setiap kriteria harus sesuai ranking yang dinilai berdasarkan tingkat prioritas. Biasanya dibentuk dengan pernyataan "kriteria 1 lebih penting dari kriteria 2, yang lebih penting dari kriteria 3" dan seterusnya hingga kriteria ke $\mathrm{n}$, ditulis, kemudian normalisasi.

\subsection{Langkah-langkah penyelesain Metode SMART}

Langkah- langkah penyelesain Metode SMART secara umum (Poningsih, n.d.) adalah sebagai berikut:

1. Menentukan kriteria yang dibutuhkan.

2. Menentukan nilai bobot dari setiap kriteria yang sebelumnya telah ditentukan sesuai nilai prioritas kriteria dengan menggunakan interval 1-100

3. Menentukan nilai normalisasi dari hasil perbandingan nilai bobot setiap kriteria dengan jumlah nilai bobot kriteria, menggunakan rumus:

$$
\frac{\boldsymbol{W j}}{\bar{\sum} \mathbf{W j}}
$$

Keterangan: $\quad W j=$ Bobot setiap kriteria $\quad \sum \mathrm{Wj}=$ Total Bobot

4. Memberikan nilai untuk setiap kriteria pada setiap alternatif. 
5. menentukan nilai ultiliti dengan mengubah nilai pada setiap kriteria, menjaddi nilai kriteria yang lebih baku, untuk nilai ultiliti didapatkan dari rumus:

$$
U i(a i)=\frac{\text { Cout }-C \min }{C \max -C \min }
$$

\section{Keterangan:}

Ui(ai) = Nilai ultiliti kriteria ke-1 untuk kriteria ke-i

Cout = Nilai kriteria ke-i

Cmin = Nilai kriteria minimal

Cmax $=$ Nilai kriteria maksimal

6. Menentukan nilai akhir dari metode ini yaitu dengan cara mengalihkan nilai ultiliti yang didapatkan dengan nilai bobot yang telah di normalisasikan, selanjutnya menjumlahkan hasil perkaliran tersebut. Rumus yang digunakan untuk mencari nilai akhir sebagai berikut :

$\mathbf{U}(\mathbf{a i})=\sum_{\mathrm{j}=\mathrm{i}}^{\mathrm{m}} \mathrm{W}_{\mathrm{j}} \mathbf{U}_{\mathbf{i}}\left(\mathbf{a}_{\mathbf{i}}\right)$

Keterangan:

$\mathrm{U}(\mathrm{ai})=$ Nilai total alternative

$\mathrm{Wj}=$ Hasil dari normalisasi bobot kriteria

Ui(ai) $=$ hasil dari penentuan nilai ultiliti

\section{Results and Discussion}

\subsection{Hasil Kuesioner}

Dari hasil semua kuesioner yang di isi oleh responden, maka penulis mendapat nilai bobot kriteria dari setiap alternatif. Dengan hasil sebagai berikut:

Tabel I Perhitungan Bobot kriteria

\begin{tabular}{ccccc}
\hline $\begin{array}{c}\text { Rata-rata } \\
\text { keseluruhan }\end{array}$ & UMUR & $\begin{array}{c}\text { JUMLA } \\
\text { H ANAK }\end{array}$ & PEKERJAAN & $\begin{array}{c}\text { BERAT } \\
\text { BADAN }\end{array}$ \\
\hline PIL KB & 56 & 49 & 34 & 45 \\
\hline SUNTIK & 62 & 57 & 46 & 55 \\
\hline IMPLANT & 66 & 52 & 46 & 49 \\
\hline IUD & 69 & 62 & 53 & 51 \\
\hline VASEKTOMI & 69 & 62 & 52 & 46 \\
\hline TUBEKTOMI & 69 & 61 & 46 & 53 \\
\hline Bobot kriteria & $\mathbf{6 5}$ & $\mathbf{5 7}$ & $\mathbf{4 6}$ & $\mathbf{5 0}$ \\
\hline
\end{tabular}

Sumber: (Maulana et al., 2021)
Untuk mendapatkan bobot kriteria menggunakan perhitungan sebagai berikut:

a) Umur $=\frac{56+62+66+69+69+69}{6}=65$

b) Jumlah anak = $\frac{49+57+52+62+62+61}{6}=57$

c) Pekerjaan $=\frac{34+46+46+53+52+46}{6}=46$

d) Berat Badan = $\frac{45+55+49+51+46+53}{6}=50$

Untuk menguji perhitungan penelitian ini menggunakan 6 langkah metode SMART, sesuai dengan alternatif dan kriteria yang telah di tentukan. Penyelesain kasus menggunakan metode sebagai berikut:

\section{A. Tahap Pertama}

Pada tahap ini dilakukan penentuan kriteria dan alternatif untuk permasalahan ini. Adapun alternatif dan kriteria sebagai berikut:

a. Alternatif terdiri dari:

$$
\begin{aligned}
& \text { A1 }=\text { Pil KB } \\
& \text { A2 }=\text { Suntik } \\
& \text { A3 }=\text { Implant } \\
& \text { A4 }=\text { IUD } \\
& \text { A5 }=\text { Vasektomi } \\
& \text { A6 }=\text { Tubektomi }
\end{aligned}
$$

b. Kriteria terdiri dari:

$$
\begin{aligned}
& \mathrm{C} 1=\text { Usia } \\
& \mathrm{C} 2=\text { Jumlah anak } \\
& \mathrm{C} 3=\text { Pekerjaan } \\
& \mathrm{C} 4=\text { Berat badan }
\end{aligned}
$$

\section{B. Tahap Kedua}

Memberi bobot kriteria sesuai tingkat kepentingan masing-masing kriteria. Nilai bobot kriteria ini berdasarkan pada penilaian pengambil keputusan yaitu penulis yang didapat dari responden. Masingmasing pengambil keputusan bisa saja memasukan nilai yang berbeda tergantung pada tingkat prefensinya terhadap setiap kriteria. Berikut kriteria sebagai berikut:

Tabel 2. Bobot Kriteria

\begin{tabular}{cc}
\hline Kriteria & Bobot \\
\hline C1 usia & 65 \\
\hline
\end{tabular}




\begin{tabular}{cc}
\hline C2 Jumlah anak & 57 \\
\hline C3 Pekerjaan & 46 \\
\hline C4 Berat badan & 50 \\
\hline TOTAL & $\mathbf{2 1 9}$ \\
\hline
\end{tabular}

Sumber: (Maulana et al., 2021)

\section{Tahap Ketiga.}

Normalisasi bobot kriteria dengan membandingkan nilai bobot setiap kriteria dengan total bobot kriteria, menggunakan rumus:

Normalisasi $W j=\frac{W j}{\underline{\Sigma W j}}$

Keterangan:

$\mathrm{Wj}=$ Bobot setiap kriteria

$\sum \mathrm{Wj}=$ Total Bobot

\section{Tabel 3. Normalisai Bobot Kriteria}

\begin{tabular}{cccc}
\hline \multicolumn{4}{c}{ Bobot kriteria } \\
\hline Kriteria & Bobot & $\sum \mathbf{W j}$ & $\mathbf{W j}$ \\
\hline C1 usia & 65 & 219 & 0,298 \\
\hline C2 Jumlah anak & 57 & 219 & 0,262 \\
\hline C3 Pekerjaan & 46 & 219 & 0,211 \\
\hline C4 Berat badan & 50 & 219 & 0,228 \\
\hline Total Wj & & $\mathbf{2 1 9}$ \\
\hline
\end{tabular}

Sumber: (Maulana et al., 2021)

\section{Tahap Keempat}

Memberikan nilai kriteria untuk masing-masing jenis alat kontrasepsi (dalam hal ini jenis kontrasepsi merupakan alternatif yang akan dipilih). Data yang didapat dari hasil kuisioner yang diisi responden sesuai tabel I perhitungan bobot kriteria. Jika dalam kasus lain data yang didapat masih dalam bentuk kualitatif maka diharuskan mengkonversinya kedalam bentuk data kuantitatif. Dengan membuat parameter kriteria yang akan di konversi.

Tabel 4. Data Alternatif

\begin{tabular}{lcccccc}
\hline \multirow{2}{*}{ Kriteria } & \multicolumn{6}{c}{ Alternatif } \\
\cline { 2 - 7 } & Pil & $\begin{array}{c}\text { Sunti } \\
\mathbf{k}\end{array}$ & $\begin{array}{c}\text { Impla } \\
\text { nt }\end{array}$ & $\begin{array}{c}\text { IU } \\
\mathbf{D}\end{array}$ & $\begin{array}{c}\text { Vasekto } \\
\mathbf{m i}\end{array}$ & $\begin{array}{c}\text { Tubekto } \\
\mathbf{m i}\end{array}$ \\
\hline Usia & 56 & 62 & 66 & 69 & 69 & 69 \\
\hline Jumlah anak & 49 & 57 & 52 & 62 & 62 & 61 \\
\hline Pekerjaan & 34 & 46 & 46 & 53 & 52 & 46 \\
\hline Berat Badan & 45 & 55 & 49 & 51 & 46 & 53 \\
\hline
\end{tabular}

Sumber: (Maulana et al., 2021)

Tabel 5. Nilai Maksimum

\begin{tabular}{cc}
\hline mencari nilai maksimal: & \\
\hline $\mathrm{Cmax}($ usia $)=$ & $\max \{56,62,66,69,69,69\}=69$ \\
\hline $\mathrm{Cmax}($ jml anak $)=$ & $\max \{49,57,52,62,62,61\}=62$ \\
\hline $\mathrm{Cmax}($ pekerjaan $)=$ & $\max \{34,46,46,53,52,36\}=53$ \\
\hline $\mathrm{Cmax}($ berat badan $)=$ & $\max \{45,55,49,51,46,53\}=55$
\end{tabular}

Sumber: (Maulana et al., 2021)

Tabel 6. Nilai Minimum

\begin{tabular}{cc}
\hline mencari nilai minimal: & \\
\hline Cmin(usia) $=$ & $\min \{56,62,66,69,69,69\}=56$ \\
\hline Cmin(jml anak $)=$ & $\min \{49,57,52,62,62,61\}=49$ \\
\hline Cmin(pekerjaan) $=$ & $\min \{34,46,46,53,52,36\}=34$ \\
\hline Cmin(berat badan) $=$ & $\min \{45,55,49,51,46,53\}=45$
\end{tabular}

Sumber: (Maulana et al., 2021)

Nilai maksimal dan minimal digunakan untuk menentukan nilai ultiliti pada tahap kelima dengan rumus yang sudah di tentukan. Hasil dari nilai maksimal didapatkan dari nilai terbesar dari masing masing jenis kriteria. Sedangkan nilai minimal didapatkan dari nilai terkecil dari masing-masing kriteria. Setelah hasil ini didapatkan maka perhitungan nilai ultiliti dapat dilakukan.

\section{E. Tahap Kelima}

Menentukan nilai ultility, pada tahap ini kita harus memperhatikan jenis masingmasing kriteria termasuk jenis'lebih besar lebih baik' atau 'lebih kecil lebih baik'. Pada kasus ini semua kriteria termasuk jenik kriteria lebih besar lebih baik,dan untuk nilai akhir yang diambil adalah nilai terendah dari Uiai. Sehingga persamaan yang digunakan adalah;

$$
\mathrm{Ui}(\mathrm{ai})=\frac{\text { Cout }-C \min }{C \max -C \min }
$$

Ui(ai) : Nilai ultility kriteria I untuk alternatif ke $\mathrm{i}$

Cmax : nilai kriteria maksimal

Cmin : nilai kriteria minimal

Cout : nilai kriteria ke i 
Setelah nilai ultiliti setiap alternative di dapatkan, maka dijadikan dalam satu tabel untuk mengetahui nilai ultiliti keseluruhan.

Tabel 7. Nilai ultiliti Alternatif

\begin{tabular}{ccccc}
\hline \multirow{2}{*}{$\begin{array}{c}\text { Nilai Ultiti } \\
\text { Alternatif }\end{array}$} & \multicolumn{4}{c}{ Kriteria } \\
\cline { 2 - 5 } & Usia & $\begin{array}{c}\text { Jumlah } \\
\text { Anak }\end{array}$ & Pekerjaan & $\begin{array}{c}\text { Berat } \\
\text { Badan }\end{array}$ \\
\hline Pil KB & 4,3 & 3,76 & 1,78 & 4,5 \\
\hline Suntik & 28,6 & 35 & 29 & 55 \\
\hline Implant & 50,7 & 12 & 29 & 19,6 \\
\hline IUD & 69 & 62 & 53 & 30,6 \\
\hline Vasektomi & 69 & 62 & 49,2 & 4,6 \\
\hline Tubektomi & 69 & 56,3 & 29 & 42,4 \\
\hline
\end{tabular}

Sumber: (Maulana et al., 2021)

\section{F. Tahap Keenam}

Menentukan nilai akhir. Menentukan nilai akhir dari metode ini yaitu dengan cara mengalihkan nilai ultiliti yang didapatkan dengan nilai bobot yang telah di normalisasikan, kemudian hasil perkalian tersebut dijumlahkan. Rumus yang digunakan untuk mencari nilai akhir sebagai berikut :

Keterangan:

$$
\mathbf{U}(\mathbf{a i})=\sum_{\mathrm{j}=\mathrm{i}}^{\mathrm{m}} \mathrm{W}_{\mathrm{j}} \mathbf{U}_{\mathbf{i}}\left(\mathbf{a}_{\mathbf{i}}\right)
$$

$\mathrm{U}(\mathrm{ai})=$ Nilai total alternative

$\mathrm{Wj}=$ Hasil dari normalisasi bobot kriteria

Ui(ai) = hasil dari penentuan nilai ultiliti

Tabel 8. Nilai Akhir

\begin{tabular}{|c|c|c|c|c|c|}
\hline \multicolumn{6}{|c|}{ Menentukan Nilai Akhir } \\
\hline \multirow{2}{*}{ Alternatif } & \multicolumn{4}{|c|}{ Kriteria } & \multirow[b]{2}{*}{ U(ai) } \\
\hline & Usia & $\begin{array}{c}\text { Jumlah } \\
\text { Anak }\end{array}$ & Pekerjaan & $\begin{array}{c}\text { Berat } \\
\text { Badan }\end{array}$ & \\
\hline Pil KB & 1,3 & 1 & 0,4 & 1 & 3,7 \\
\hline Suntik & 8,5 & 9,2 & 6,1 & 12,5 & 36,4 \\
\hline Implant & 15,1 & 3,1 & 6,1 & 4,5 & 28,9 \\
\hline IUD & 20,6 & 16,3 & 11,2 & 7 & 55 \\
\hline Vasektomi & 20,6 & 16,3 & 10,4 & 1 & 48,3 \\
\hline Tubektomi & 20,6 & 14,8 & 6,1 & 9,7 & 51,2 \\
\hline
\end{tabular}

Sumber: (Maulana et al., 2021)

Hasil akhir bila diurutkan berdasarkan rangking adalah sebagai berikut:
Tabel 9. Ranking

\begin{tabular}{ll}
\multicolumn{1}{c}{$\begin{array}{c}\text { Hasil } \\
\text { akhir }\end{array}$} & Keterangan \\
\hline Pil KB & Ranking 1 \\
\hline Implant & Ranking 2 \\
\hline Suntik & Ranking 3 \\
\hline Vasektomi & Ranking 4 \\
\hline Tubektomi & Ranking 5 \\
\hline IUD & Ranking 6
\end{tabular}

Sumber: (Maulana et al., 2021)

Berdasarkan kasus tersebut, alat kontrasepsi yang cocok untuk pasangan usia subur adalah jenis kontraseepsi PIL KB. Dengan nilai akhir ultiliti terkecil dengan nilai akhir $\mathrm{U}(\mathrm{ai})=3,7$.

\subsection{Results and Discussion}

Berdasarkan pengamatan dan pengolahan data serta analisa sebelumnya, penulis dapat menyimpulkan bahwa:

1. Penulis menggunakan metode SMART (Simple Multi Attribute Rating Tachnique) sebagai sistem penunjang keputusan pemilihan alat kontrasepsi terbaik untuk pasangan usia subur.

2. Selama melakukan penelitian, penulis menggunakan sampel yang berasal dari pasangan usia subur.

3. Dalam pengolahan data, menggunakan empat kriteria (Usia, jumlah anak, pekerjaan, berat badan) dan enam alternatif yaitu( Pil KB, Suntik, Implant, IUD, Vasektomi, Tubektomi).

4. Setelah melakukan pengolahan dan analisa data responden, diperoleh hasil sebagai berikut:

a. Pil $\mathrm{Kb}$ memiliki nilai akhir U(ai) yaitu:3,7

b. Suntik memiliki nilai akhir U(ai) yaitu: 36,4

c. Implant memiliki nilai akhir U(ai) yaitu:28,9

d. IUD memiliki nilai akhir U(ai) yaitu: 55,0 
e. Vasektomi memiliki nilai akhir $\mathrm{U}(\mathrm{ai})$ yaitu: 48,3

f. Tubektomi memiliki nilai akhir $\mathrm{U}(\mathrm{ai})$ yaitu: 51,2

Dari hasil data di atas dapat disimpulkan bahwa alternatif terbaik untuk pemilihan alat kontrasepsi terbaik adalah jenis Pil KB dengan tingkat data terkecil. Karena semakin kecil data tersebut diartikan tidak banyak memiliki kendala dalam penggunaan alat kontrasepsi. Penelitian ini berbeda dengan penelitian sebelumnya, penelitian sebelumnya yang dilakukan oleh (Naafian et al., 2016) fokusnya adalah melakukan prediksi, dan penelitian yang dilakukan oleh (Meilani \& Tunggali, 2020) berfokus pada Hubungan karakteristik ibu dengan pemilihan alat kontrasepsi dalam rahim (AKDR).

\subsection{Conclusions}

Berdasarkan penelitian Sistem Pendukung Keputusan Pemilihan Alat Kontrasepsi Terbaik Metode Smart ( Simple Multi Attribute Rating Technique ) Bagi Keluaraga Berencana, disimpulkan bahwa alternatif untuk pemilihan alat kontrasepsi terbaik adalah jenis Pil KB dengan tingkat data terkecil. Karena semakin kecil data tersebut diartikan tidak banyak memiliki kendala dalam penggunaan alat kontrasepsi. Penelitian pemilihan alat kontrasepsi dengan menggunakan metode SMART sudah cukup baik serta metode yang mudah dipahami dalam pengolahan data, tetapi metode SMART juga memiliki kelemahan salah satunya adalah metode SMART mengabaikan hubungan timbal balik antar parameter. Diharapkan penelitian berikutnya dapat meningkatkan performa dari metode SMRAT atau juga dapat dengan menggunakan metode yang lain.

\subsection{References}

Andani, S. R. (2019). Metode Simple Multi Attribute rating Technique (SMART)
Dalam Menentukan Penerima Dana Bantuan Yayasan AMIK Tunas Bangsa. J-SAKTI (Jurnal Sains Komputer Dan Informatika), 3(2), 160. https://doi.org/10.30645/j-

sakti.v3i2.135

Herlinda, H., \& Husain, H. (2019). Analisis Sistem Penunjang Keputusan Dengan Metode Simple Multi Attribute Rating Technique (Smart) Untuk Uji Kelayakan Operational Bus. SENSITIf: Seminar Nasional Sistem Informasi Dan Teknologi Informasi, 539-545.

Irawan, Y., Wahyuni, R., Informasi, S., \& Informatika, T. (2019). SISTEM PENDUKUNG KEPUTUSAN PENERIMAAN SISWA BARU DI SMK NEGERI 1 TAPUNG HULU MENGGUNAKAN METODE SIMPLE MULTI ATTRIBUT RATING TECHNIQUE ( SMART ). 3(1), 25-31.

Lontaan, A., \& Dompas, R. (2014). Faktor - Faktor Yang Berhubungan Dengan Pemilihan Kontrasepsi Pasangan Usia Subur Di Puskesmas Damau Kabupaten Talaud. 2(1), 27-32.

Maulana, R., Suryani, N., \& Buani, D. C. P. (2021). SISTEM PENDUKUNG KEPUTUSAN PEMILIHAN ALAT KONTRASEPSI TERBAIK METODE SMART ( SIMPLE MULTI ATTRIBUTE RATING TECHNIQUE ) BAGI KELUARAGA BERENCANA. Penelitian Mandiri 2021 .

Meilani, M., \& Tunggali, A. P. P. W. (2020). Pemilihan Alat Kontrasepsi dalam Rahim (AKDR) pada akseptor Keluarga Berencana. Jurnal Kebidanan, $\quad 9(1), \quad 31$. https://doi.org/10.26714/jk.9.1.2020.31 $-38$

Naafian, N. R., Siswanti, S., \& Saptomo, W. L. Y. (2016). Sistem Pendukung Keputusan Pemilihan Metode 
Kontrasepsi Di Puskesmas Ii Colomadu Dengan Algoritma Naïve Bayes. Tikomsin, 10, 1-10.

Novianti, D., Astuti, I. F., \& Khairina, D. M. (2016). Sistem Pendukung Keputusan Berbasis Web Untuk Pemilihan Café Menggunakan Metode Smart ( Simple Multi-Attribute Rating Technique ) ( Studi Kasus: Kota Samarinda ). Prosiding Seminar Sains Dan Teknologi FMIPA Unmul, 461465.

Poningsih. (n.d.). Sistem Pendukung Keputusan: Penerapan \& 10 COntoh Studi Kasus. YAYASAN KITA MENULIS.

Safii, M., \& Anggi Saputri, D. (2018). Penerapan Metode Simple Multi Attribute Rating Technique (Smart) Sebagai Motivasi Pegawai Dalam Peningkatan Prestasi. Terakreditasi DIKTI, 2(2), 169-174.

Saleh, A. (2018). Penerapan Metode Simple Multi Attribute Rating Technique Exploiting Rank dalam Sistem Pendukung Keputusan Rekrutmen Asisten Laboratorium Komputer. Masyarakat Telematika Dan Informasi, 8, 1-10.

Studi, P., Masyarakat, K., Ilmu, F., Universitas, K., Bogor, I. K., Studi, P., Masyarakat, K., Ilmu, F., Universitas, K., Khaldun, I., Studi, P., Masyarakat, K., Ilmu, F., Universitas, K., \& Khaldun, I. (2018). Kata Kunci: IUD, pengetahuan, dan dukungan suami.
1(1).

Suryanto, \& Safrizal, M. (2015). Sistem Pendukung Keputusan Pemilihan Karyawan Teladan dengan Metode SMART (Simple Multi Attribute Rating Technique). Jurnal CoreIT, 1(2), 25-29. 